\title{
SPRING 2021: CLINICIAN INVESTIGATOR TRAINEE ASSOCIATION OF CANADA (CITAC)
}

VOL 44 NO 1 MARCH 2021 \author{
Heather T. Whittaker, $\mathrm{MSc}^{5}$, Adam Pietrobon, $\mathrm{BSC}^{1}$ \\ 1 Faculty of Medicine, University of Ottawa, ON, Canada \\ 2 School of Medicine, Queen's University, Kingston, ON, Canada \\ Cumming School of Medicine, University of Calgary, AB, Canada \\ Schulich School of Medicine and Dentistry, Western University, London, ON, Canada \\ Faculty of Medicine and Health Sciences, McGill University, Montreal, QC, Canada \\ Clin Invest Med 2021;44(1):E1-4; DOI: 10.25011/cim.v44i1.36102 \\ Correspondence to: Melissa S. Phuong Email: mphuo060@uottawa.ca
}

Melissa S. Phuong, BHSc${ }^{1}$, Valera Castanov, $\mathrm{PhD}^{2}$, Sophie $\mathrm{Hu}, \mathrm{MSc}^{3}$, Danny Jomaa, $\mathrm{MSc}^{2}$, Wenxuan Wang, $\mathrm{BSc}^{4}$,

\section{Message from the President: The evolving role of CITAC}

The Clinician Investigator Trainee Association of Canada (CITAC) was established in 2006, uniting clinician-investigator $(\mathrm{Cl})$ trainees across the country around the common goal of improving training conditions for those pursuing a career at the junction of research and medicine. Since then, the $\mathrm{Cl}$ training landscape has shifted dramatically. The number of Canadian $\mathrm{Cl}$ trainees enrolled in formal programs has reached record numbers, totalling $289 \mathrm{MD}-\mathrm{PhD}$ trainees and 389 Clinical Investigator Program (CIP) trainees as of 2019 [1]. Alumni outcome data have presented conclusive evidence that MD-PhD training programs are effective in producing $\mathrm{Cl}$ careers [2-4]. Despite successes, long-standing challenges to the $\mathrm{Cl}$ training pathway persist, including lack of integration, career guidance and funding [5-7]. While definitive recommendations for improving Canadian $\mathrm{Cl}$ training have been made [8], change has lagged. The needs of $\mathrm{Cl}$ trainees over the years have evolved and so too must CITAC evolve to meet those needs.

This past year, CITAC underwent a major restructuring of our Board of Directors and leadership team. We have collapsed our large team to a smaller group-with more encompassing portfolios (Figure 1). New positions have also been created, including the Directors of Researchto accelerate CITAC's evidence-generating capacity, and the Director of Student Affairs-to expand programming and resources for $\mathrm{Cl}$ trainees. We have also introduced appointed Chair positions to assist in conducting CITAC's critical activities.

Looking to the future, the Board has initiated a compre- hensive strategic planning process; re-envisioning the role of CITAC and how we can best meet the needs of trainees. While planning is ongoing, important themes have already emerged: 1) improving the recruitment, retention and support of underrepresented groups in $\mathrm{Cl}$ training pathways; 2) fostering interaction among the national clinician-investigator trainee network; and 3) expanding services to $\mathrm{Cl}$ trainees not enrolled in formal dual-training programs. We are excited to share this plan with you in the coming months and welcome all feedback.

\section{Virtual AGM 2020 Highlights}

In light of the ongoing pandemic and like many other conferences, CITAC's 2020 Annual General Meeting (AGM) went virtual. The event was hosted as a collaboration with the University of Toronto's Integrated Physician Scientist Training Program. Quite succinctly: it was a marked success! We had a record number of participants, with exactly 200 registrants and at least one trainee from each institution across Canada (Figure 2). Importantly, in comparison with previous years, we observed a broader distribution of participants by school and training pathway. Post-AGM survey data has indicated substantial satisfaction with the conference format, workshop content, and plenary sessions. Stay tuned for the official conference overview and abstract summary.

The majority of Canadian clinician-investigator trainees are considering additional training outside Canada

A perpetual question for many clinician-scientist trainees is the value of international training, and whether such a route should be pursued in one's training path. 
FIGURE 1.

STRUCTURAL CHANGE TO THE NEW CITAC BOARD OF DIRECTORS AND LEADERSHIP TEAM

New CITAC Board Structure

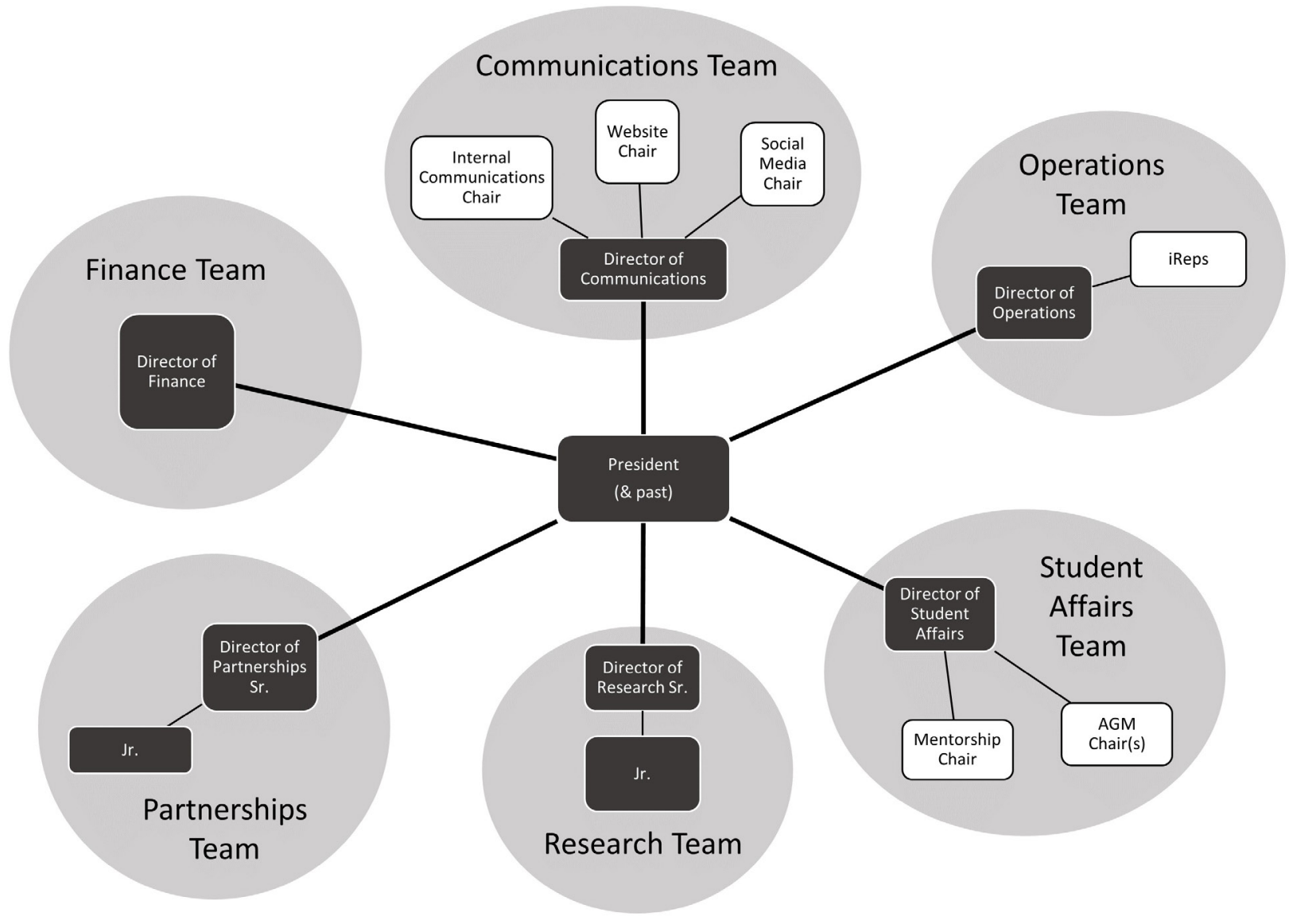

FIGURE 2.

AGM 2020 PARTICIPANT STATISTICS. A) NUMBER OF REGISTRANTS, BY SCHOOL. B) NUMBER OF REGISTRANTS, BY TRAINING PATHWAY
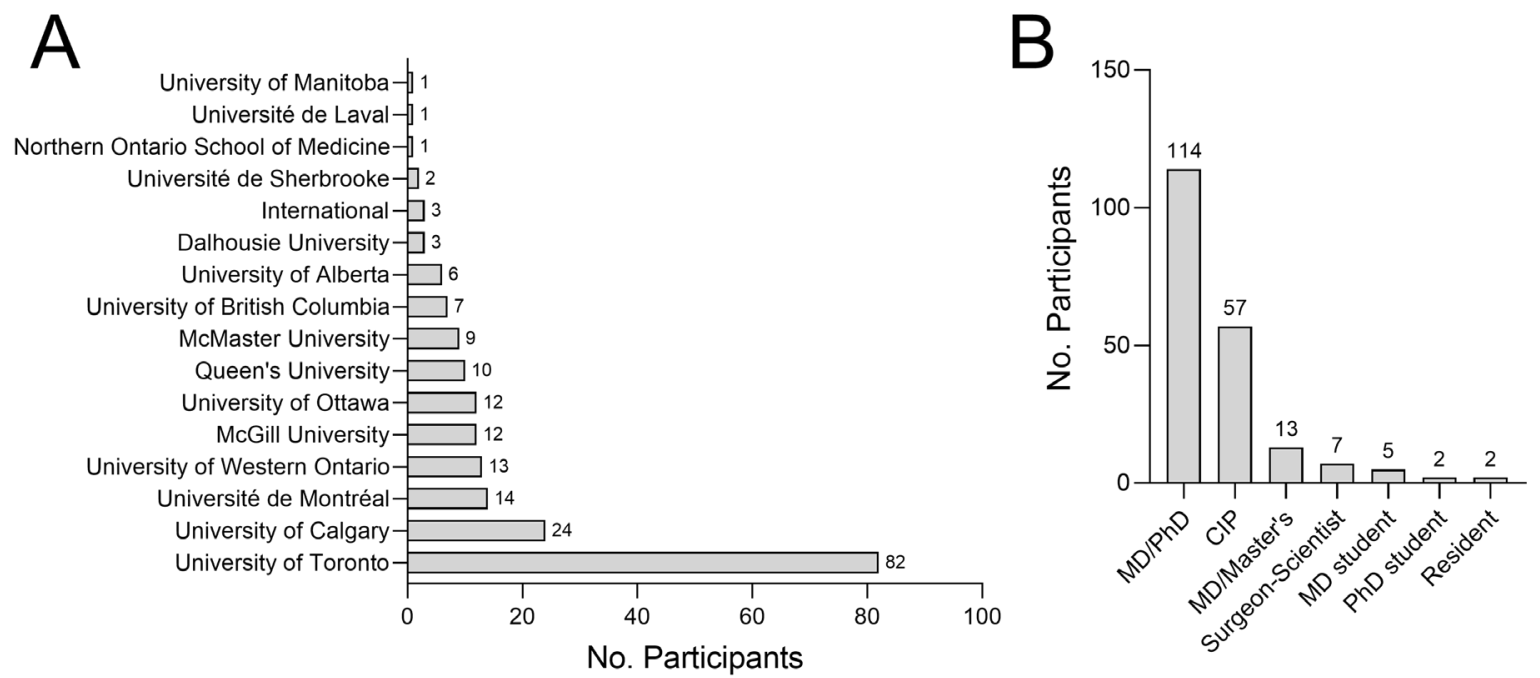
This past year, CITAC conducted a national survey on this topic [1]. Remarkably, $63 \%$ of Canadian $\mathrm{Cl}$ trainees were considering completing additional training internationally. What this means for the future of Canada's Cl training landscape remains unknown; however, more work needs to be done to support this mobility and/or improve domestic training opportunities.

Adam Pietrobon

MD/PhD Student

CITAC President (2020-2021)

CITAC LEADERSHIP TEAM 2021

Board of Directors

- President - Adam Pietrobon

- Past President - Tina Marvasti

- Director of Communications - Melissa Phuong

- Director of Operations - Heather Whittaker

- Director of Student Affairs - Wenxuan Wang

- Director of Research Sr. - Andy Zeng

- Director of Research Jr. - Bryce Bogie

- Director of Partnerships Jr. - Danny Jomaa

- Director of Partnerships Sr. - Sophie Hu

- Director of Finance - Matthaeus Ware

Portfolio Chairs

- Internal Communications Chair - Jillian Macklin

- Social Media Chair - Valera Castanov

- AGM Co-Chair - Emma LeBlanc

- AGM Co-Chair - Sangmin (Sarah) Lee

- Mentorship Chair - Yujin Suk

MESSAGE FROM DIRECTORS OF PARTNERSHIPS The CITAC's new Director of Partnerships portfolio has absorbed and expanded upon the previous responsibilities of the VP External. This year, our team has been working to characterize $\mathrm{Cl}$ training pathways across the world with the International Consortium of Clinician Scientist Training Organizations (ICCSTO; https://www. citac-accfc.org/images/2020/ICCSTO-press-release-English ud.pdf), which connects representatives from $\mathrm{Cl}$ trainee organizations in Canada, the United States, France, Switzerland, Europe and Asia. Stay tuned for a survey to assess trainee programs and outcomes. The Partnerships team is also connecting with potential academic, research and industry partners to engage trainees in resources and opportunities that will support your career development. As well, we are collaborating with $\mathrm{CSCl}$ and medical schools across Canada to develop a monthly seminar series with relevant topics to trainees including equity, diversity and inclusion; working in industry; and mentorship. Please let us know which topics you are interested in!

Sophie Hu and Danny Jomaa

\section{MESSAGE FROM DIRECTOR OF COMMUNICATIONS}

For this year, our primary goal has been to increase the frequency of communication with CITAC members. We have been piloting a new submission form so that CITAC members are able to share events or initiatives through our listserv. As always, we will be continuing our "Humans of CITAC" initiative and are looking forward to sharing profiles on $\mathrm{Cl}$ trainees throughout Canada. We encourage use of both submission forms, which will be made available via our emails, to engage with the wider CITAC network. As well, a team is working with a web developer to construct a new CITAC website. We are excited to introduce a modern layout and exclusive CITAC members content in the coming months.

Melissa Phuong

\section{MESSAGE FROM DIRECTOR OF STUDENT AFFAIRS}

The Student Affairs portfolio is responsible for the development and expansion of services and resources for clinician-scientist trainees. Our focus will be 1) organization of the Mentorship Match between trainees and clinician-scientist faculty members, 2) distribution of the US Residency Handbook and 3) overseeing the planning of the CITAC Annual General Meeting.

New this year: we are creating a career development seminar series in collaboration with $\mathrm{CSCl}$ (Canadian Society for Clinical Investigation) for MD/PhD and CIP trainees.

The current availability of career-focused workshops varies widely across training centers; however, we recognize that all Canadian trainees face similar challenges and would benefit from broader discussions on how to navigate the unique clinical and research demands. This initiative aims to create a national career development program that widens the accessibility and reach of the various workshops. By centering each monthly seminar around a provocative question, we will provide a platform for trainee networking through interactive discussions, and further strength the $\mathrm{Cl}$ community.

\section{Wenxuan Wang}

\section{MESSAGE FROM DIRECTOR OF OPERATIONS}

It is integral to our mission that CITAC truly represents the interests of $\mathrm{Cl}$ trainees across the country and offers valuable services to our members. In the past, we have relied on a dedicated group of institutional representatives (iReps) to reach our members, but communication was not always bidirectional. This year, we aim to strengthen connections with and among our members by establishing CITAC's first ever Representative Advisory Committee (RAC). The RAC will include MD+ trainees from 
all Canadian training institutions as well as representatives from relevant organizations, such as the Canadian Federation of Medical Students, and will meet regularly to inform ongoing and future CITAC initiatives.

Heather Whittaker

\section{RESOURCES FROM MD FINANCIAL MANAGEMENT}

Rent or buy: What to think about before you decide

Buying a home can be scary-it may be the largest purchase of your life, especially if you are in the Toronto or Vancouver areas. This massive financial commitment could tie up your finances for the foreseeable future. We listed some considerations for you to make an informed decision. Read more.

Tax planning in a pandemic: How to adjust for 2021

Did you experience reduced patient care and reduced income in 2020? The year was different from the rest. Your financial and tax planning strategy going forward could look different too. Which COVID-19 government support programs are taxable? Is your retirement plan due for a reset? You can stay on track and still meet your goals by adjusting your financial plan. Start laying the groundwork for some stability in 2021 with seven considerations. Read more.

\section{REFERENCES}

1. Pietrobon A, Cook EK, Yin C, Chan DCH, Marvasti TB. International training considerations of Canadian Clinician-Scientist Trainees - A national survey. Clin Invest Med. 2020;43(4):E2-7. doi:10.25011/cim.v43i4.35003

2. Zhou TE, Savage PA, Eisenberg MJ. Canadian M.D.-Ph.D. Programs Produce Impactful Physician-Scientists: The McGill Experience. J Biomed Educ. 2016; 3836467. doi:10.1155/2016/3836467

3. Skinnider MA, Squair JW, Twa DDW, et al. Characteristics and outcomes of Canadian MD/PhD program graduates: a cross-sectional survey. CMAJ Open. 2017;5(2):E308-E314. doi:10.9778/cmajo.20160152

4. Bau JT, Frolkis AD, Nathoo N, Yipp BG, Hollenberg MD, Beck PL. Career and research outcomes of the physician-scientist training program at the University of Calgary: a retrospective cohort study. CMAJ Open. 2017;5(2):E395-E401. doi:10.9778/cmajo.20160103

5. Jones AA, Ng E, Deguise M-O, et al. MD/PhD Training in Canada: Results from a national trainee and program director review. Clin Invest Med. Published online September 11, 2016:E132-E139.

6. Ballios BG, Rosenblum ND. Challenges Facing Physician Scientist Trainees: a Survey of Trainees in Canada's Largest Undergraduate and Postgraduate Programs in a Single Centre. Clin Invest Med. Published online October 4, 2014:E268-E283.

7. Pietrobon A, Chehadé L, Beaudry-Richard A, Keller BA, Schlossmacher MG. Performance report for a 10-year-old MD/PhD Program: A survey of trainees at the University of Ottawa. Clin Invest Med. 2020;43(2):E1-13. doi:10.25011/cim. v43i2.33955

8. Strong MJ, Busing N, Goosney DL, et al. The Rising Challenge of Training Physician-Scientists: Recommendations From a Canadian National Consensus Conference. Acad Med. 2018;93(2):172-178. doi:10.1097/ACM.0000000000001857 